\title{
ISRAEL NO TRÓPICO? MULHERES CRIPTOJUDIAS E IDENTIDADES RELIGIOSAS NO BRASIL COLONIAL
}

\author{
Angelo Adriano Faria de Assis*
}

\section{Resumo}

Este artigo tem como objetivo analisar a sobrevivência do judaísmo durante o período de monopólio católico implementado no mundo português em fins do século XV. Os judeus batizados, denominados cristãos-novos, seriam suspeitos de manter ocultamente as práticas e crenças judaicas, e considerados ameaça ao catolicismo. A resistência judaica, ou criptojudaísmo, teve nas mulheres papel fundamental para sua sobrevivência. Aqui nos interessa perceber as práticas criptojudaicas no Brasil colonial, a partir da documentação produzida pelo Tribunal do Santo Ofício da Inquisição.

Palavras-chave: Inquisição, mulheres, resistência judaica, Brasil colonial

\section{Abstract}

This article aims to analyze the survival of Judaism during the Catholic monopoly implemented in the Portuguese World in the end of fifteenth century. The Jews baptized, called New Christians, were suspected of secretly maintaining Jewish practices and beliefs, and considered threat to Catholicism. Women were central to this Jewish survival. Here we are interested in realizing the hidden Jewish practices in colonial Brazil, from the documentation produced by the Tribunal of the Holy Office of the Inquisition.

Keywords: Inquisition, women, Jewish resistance, colonial Brazil

* Doutor em História pela Universidade Federal Fluminense. Professor adjunto da Universidade Federal de Viçosa. <angeloassis@uol.com.br> 
$\mathbf{N}$ as últimas décadas, ganhou destaque o grande o número de trabalhos científicos que contribuíram para dar nova ênfase ao estudo sobre a cultura e a religiosidade no mundo ibero-americano. Muitas destas pesquisas, inclusive, ultrapassaram os limites da Academia e chegaram até o grande público, por conta do aumento das publicações de obras na área das Ciências Humanas e da História, em particular. Em complemento a isto, o surgimento de outros filões editoriais e de entretenimento, como a publicação de revistas e magazines especializados, tem incentivado a produção de filmes e programas televisivos, o aumento da procura de livros de romances históricos, a difusão de informações pela internet, entre outros exemplos, demonstram um interesse vivo e generalizado pelo passado.

Outro fato a destacar, cabe dizer, é que o atual momento de crescimento econômico e desenvolvimento social do país, assim como a democratização do acesso ao ensino - dos primeiros anos à formação superior -, nas últimas décadas demonstrou uma carência generalizada de professores nas mais diversas áreas, a História aí incluída. Apesar dos avanços, ainda é possível perceber uma grande carência de profissionais, que repercute numa espécie de caminho na contramão de outros países: enquanto algumas nações, seja por conta de já terem resolvido os problemas básicos de seu sistema de ensino, seja pela baixa demanda natural, encontram certa dificuldade em preencher as vagas oferecidas nas universidades para os futuros historiadores; no Brasil, ao contrário, a realidade mostra o crescimento - ou, pelo menos, a manutenção - nos índices de procura por vagas em cursos de terceiro grau para os que desejam trabalhar tanto com o ensino, nos mais variados níveis, quanto com a pesquisa, ambos fundamentais neste resgate e reconstrução da memória do passado.

No que diz respeito ao campo científico, este processo é ainda alimentado pelo fortalecimento dos programas de pós-graduação no Brasil, mas também, em boa parte, pelo aquecimento do debate entre pesquisadores brasileiros com seus pares de outros lugares do mundo, tais como Estados Unidos, Europa e América Latina, da mesma forma que pela maior frequência com que os arquivos destes países são visitados por pesquisadores do Brasil (e o inverso, ainda bem, também é verdadeiro). Enfim, o fato é que hoje se produz, inegavelmente, uma historiografia de qualidade no país, e cada vez mais esta historiografia dialoga com centros de documentação e pesquisa e pesquisadores de outras 
nações, numa troca mútua de experiências que enriquece incontestavelmente o debate científico e propicia a disseminação de ferramentas e metodologias de pesquisa.

E a abertura vivida pela História nas últimas décadas, influenciada pela onda de transformações sofridas a partir da Histórica das Mentalidades, tem permitido a aproximação com outros campos do conhecimento e da produção de Cultura, tais como a Geografia, a Sociologia e a Literatura, entre tantas outras possibilidades.

Mas aqui nos interessa refletir sobre o ramo de pesquisa em que nos situamos - a presença sefardita e as origens da criação do Tribunal do Santo Ofício em Portugal, bem como a sua atuação no mundo colonial brasílico, tendo como foco de análise seus alvos preferenciais: os cristãos-novos, judeus batizados em 1497 e seus descendentes, perseguidos pela Inquisição como suspeitos de judaizar em segredo, ou criptojudaizar, como se dizia no jargão da época.

Os estudos sobre a ação do Santo Ofício e a perseguição às suas vítimas têm avançado consideravelmente no Brasil, desde os trabalhos que, a partir principalmente das décadas de 1960 e 1970, mostraram-se pioneiros, como os trabalhos inaugurais de Elias Lipiner em Os judaizantes nas capitanias de cima (1969), Anita Novinsky em Cristãos-novos na Bahia (1972), Sonia Siqueira em A Inquisição portuguesa e a sociedade colonial (1978), entre outros, que influenciaram e influenciam novas levas de pesquisadores.

Hoje, uma nova geração dá continuidade aos estudos inquisitoriais na Academia. Contam, entre outras vantagens, com a facilidade de acesso aos arquivos da Inquisição, digitalizados e disponibilizados para consulta on-line, democratizando o acesso para os que desejam conhecer estes importantes conjuntos documentais referentes à modernidade luso-brasílica. Mais além, todos estes trabalhos contribuíram para que outros pesquisadores desenvolvam e venham a se interessar por pesquisas de mestrado e doutorado sobre a temática.

Enquanto no Brasil os estudos sobre a ação e as vítimas do Santo Ofício ganham espaço, em Portugal, onde estão localizados os documentos produzidos pelo e em nome do Santo Ofício - no Arquivo Nacional da Torre do Tombo, em Lisboa -, o quadro é outro, e as pesquisas sobre a Inquisição e seus perseguidos encontram menor espaço. Fica, então, um apelo e um convite para que os novos pesquisadores portugueses redobrem os esforços e retomem os 
estudos sobre o funcionamento e a atuação inquisitorial portuguesa, bem como sobre os indivíduos que foram denunciados à Misericordia et Justitia.

A história dos cristãos-novos e da instauração do Tribunal do Santo Ofício da Inquisição em Portugal tem início em fins do século XV. Em dezembro de 1496, o monarca português, D. Manuel I, repetindo o que havia ocorrido quatro anos antes na vizinha Espanha, decretaria a expulsão dos judeus e mouros forros do reino, dando um prazo de dez meses para que deixassem Portugal. Finda esta data, em outubro de 1497, uma reviravolta: levando em conta o papel que os judeus representavam para Portugal naquele momento de expansão ultramarina o monarca acabou transformando-os em cristãos-novos e proibindo-os de sair do reino.

Os neoconversos seriam vistos como suspeitos de comungar as antigas crenças e, por conseguinte, de falta de adesão completa e sincera ao cristianismo. Os cristãos-novos descendentes de judeus eram vistos, pela população em geral, como a grande ameaça à pureza cristã. E o fato é que muitos deles mantinham ocultamente, em graus e formas variados, as práticas e crenças dos antepassados, sendo por conta disto denominados judeus ocultos ou criptojudeus.

Mas a conversão oficial não significava, no mesmo grau, a conversão de fato, e a sociedade portuguesa rapidamente reconhecia no processo de implantação do monopólio católico a causa para a diminuição da pureza cristã no reino. Tanto os judeus quanto os mouros convertidos, seja por fidelidade à antiga fé, seja por desconhecimento das normas católicas, mantinham comportamentos tidos como desviantes da retidão cristã, palco para o acirramento das relações sociais. Os cristãos-novos passariam a ser vistos como cristãos de segunda classe, que colocavam em risco a pureza da religião dominante.

A necessidade de controle sobre as ameaças ao catolicismo - o criptojudaísmo considerado a maior delas - levaria a negociações da monarquia portuguesa junto ao papado para a instauração do Tribunal da Inquisição em território luso, o que ocorreria no ano de 1536, durante o reinado de D. João III. Com a instauração da Inquisição, e a posterior estruturação do Santo Ofício no reino, aumentaria o clima de perseguições e hostilidades contra o grupo neoconverso, e o permanente controle inquisitorial acabaria por alimentar profundas transformações nas relações sociais e no convívio entre cristãos velhos e novos, 
intensificando as hostilidades e as delações de comportamentos tidos como desviantes aos representantes do Santo Tribunal. Por conta disto, não foram poucos os cristãos-novos que optaram por migrar para outras regiões, fugindo do Santo Ofício.

Assim, em menos de meio século (de 1496 a 1536), a constituição da sociedade portuguesa foi profundamente modificada: do milenar convívio relativamente harmônico entre judeus, mouros e cristãos, passava-se à implantação do monopólio católico e à perseguição aos que não eram considerados cristãos inteiros ou puros, tuteladas por um tribunal eclesiástico instaurado para moldar e controlar o comportamento religioso dos fiéis do reino (ou seja, com a conversão forçada, todos os habitantes de Portugal), punindo exemplarmente aqueles considerados desviantes da verdadeira fé - os cristãos novos em primeiro lugar.

Via máquina inquisitorial, mesmo de forma intolerante e equivocada visse um judaizante em potencial em cada cristão-novo, tinha razão em perceber que o judaísmo continuava ativo em Portugal no período pós-conversão forçada. Claro, não estamos a defender ou justificar a lógica da perseguição inquisitorial e as abomináveis medidas de punição impostas aos réus do Santo Ofício - muitíssimo longe disto -, mas é verdade que uma considerável parcela dos neoconversos continuou a tentar manter vivas as tradições da religião mosaica. As denúncias, confissões e processos inquisitoriais são a prova disto. Guardados os exageros dos denunciantes e o olhar viciado tanto da sociedade quanto de muitos representantes do Santo Ofício, que viam em qualquer comportamento diferenciado da prática católica uma prova inequívoca de judaísmo, o certo é que muitos judeus continuaram, dentro das possibilidades - muitas vezes, ínfimas -, a manter fidelidade à fé de Moisés, judaizando em segredo, em boa parte, em família, na privacidade do lar.

Mas, no século XVI, principalmente nas primeiras décadas, no momento anterior ao surgimento da Inquisição, quando muitos dos antigos judeus, inclusive os que foram rabinos, ainda continuavam vivos e guardavam a memória judaica, com a manutenção de algumas festas e práticas e o acesso a textos sagrados, o judaísmo sobreviveu e foi repassado aos descendentes. Conforme afastamo-nos do período de conversão forçada, contudo, algumas práticas mais denunciadoras da manutenção judaica foram sendo abandonadas em prol 
de outros comportamentos que permitiam, aos criptojudeus, manterem sua fé sem serem percebidos. Então, acabavam por substituir celebrações públicas da fé, como festas, uso de trajes típicos ou preparação de determinados alimentos, por comportamentos menos denunciadores, como jejuns e orações realizadas em particular. Mas, no geral, a prática do judaísmo ainda era evidente, a ponto de alguns apelos pela conversão ganharem força, inclusive na forma de tratados, como o texto-advertência de Frei Francisco Machado em 1541, Deixai a Lei de Moisés! (VAINFAS, 2005).

Contudo, tendo suas bases bastante enfraquecidas devido às perseguições e impedimentos que foram impostos, os rituais judaicos sofreriam, ao longo do tempo, alterações das mais diversas, no intuito de - adaptados à nova e hostil realidade - não só evitar a perseguição aos seus adeptos, mas também de impedir o seu completo desaparecimento, permitindo uma sobrevida em um quadro de hostilidade, suficiente para que as novas gerações pudessem conhecer e comungar a fé e costumes dos antepassados.

Neste quadro, agiganta-se o papel destinado à mulher na preservação judaica. Se, numa situação de normalidade, aos homens eram destinadas as posições de destaque na prática cotidiana dos ideais hebraicos, a situação proibitiva e desfavorável criada no mundo português levaria as mulheres a subverterem esse quadro, ocupando papel primordial na divulgação deste judaísmo adaptado, dissimulado e diminuto que se tornara possível, tornando-se, sem dúvida, das principais responsáveis pela resistência e organização de suas novas bases durante os séculos em que a crença mosaica só ganhava eco às escondidas.

Não por acaso, a estruturação da Inquisição em Portugal e o consequente aumento das perseguições aos neoconversos a partir da década de 1540 , com a realização dos primeiros autos de fé no reino, significaram o aumento das migrações de cristãos-novos para a colônia luso-americana, onde a produção de açúcar ganhava destaque e transformava o trópico luso-brasílico em ponta de lança da economia do império português. No Brasil, estes cristãos-novos se "enobreciam" como era possível, visto as proibições legais para alcançarem cargos de nobreza: economicamente eles galgavam posições, transformados em destacados senhores de engenho, muitos deles homens riquíssimos e com grande influência, com ligações com os principais da terra, catapultados a figuras de destaque da sociedade colonial. Não raro, mantinham ligações com 
outros cristãos-novos migrados para outros espaços do vasto império luso Cochim, Goa, Macau, Moçambique, Guiné, Malaca, Angola, São Tomé, Madeira... -, negociando seus produtos e circulando informações que, no limite, ajudavam a proteger o grupo neoconverso das perseguições da "Santa Forca".

Prova do bom convívio entre os cristãos novos e velhos na colônia encontrase tanto na presença dos neoconversos em praticamente todos os espaços da economia, imbricando-se nos mais diversos níveis sociais, como no grande número de casamentos mistos entre cristãos velhos e novos, ratificando a maior aceitação social destes enlaces e a diluição dos atritos no convívio entre os grupos na região brasílica, se comparado ao quadro vivenciado no reino.

Na colônia, as longas distâncias a serem vencidas com dificuldade acabaram por intensificar ainda mais o papel que já no reino havia sido destinado à mãe neoconversa, responsável por ensinar no abrigo do lar as primeiras lições mosaicas aos rebentos. As mulheres eram responsáveis não só pela organização e limpeza da casa, preparando alimentos e cuidando da saúde e educação dos filhos. Eram, não raro, responsáveis pela segurança do lar, pela provisão de mantimentos, pela manutenção da ordem e ensino das primeiras letras, e lições de moral aos filhos. Na falta do pai, assumiam o comando da casa e da educação dos filhos, assumindo o tripé mãe-educadora-rabi. Foram essas mulheres, sem dúvida, os baluartes do judaísmo oculto, lutando por sua resistência em um quadro totalmente hostil, divididas entre a proteção dos filhos e do segredo da antiga fé.

Conforme vimos, no ambiente de proibição que o judaísmo enfrentou a partir do final dos anos quatrocentos em Portugal e seus domínios, a casa transformouse no lugar do culto, em substituição às sinagogas. No Brasil colonial, como na luso-ibéria, era possível ser judeu, e o núcleo familiar, com as mulheres à frente, é que tornou possível esta sobrevivência. Transmitindo os ritos religiosos ao praticá-los nas residências, realizavam o rabinato diminuto, feminino e oral que se tornara possível e que, embora contrariasse o códice mosaico, garantiu-lhe resistir. É o que afirma Elias Lipiner, ao lembrar o que se dizia à época das mulheres neoconversas, que, "devotas e rezadeiras, iam nos domingos e dias santos ouvir missa", procurando vencer as desconfianças generalizadas sobre sua real entrega ao catolicismo, "mas nos sábados vestiam seus melhores vestidos" (LIPINER, 1969, p. 46), preparando-se para o sagrado dia de descanso dos judeus, reunindo a família para celebrar os costumes de seus antepassados. 
Esta nova importância destinada à mulher cristã-nova não passaria em branco para os representantes do Santo Ofício, os quais, rapidamente perceberam a necessidade de verificar a religiosidade vivida no Brasil. Um dos locais dos preferidos pelos cristãos-novos portugueses que escolhiam a diáspora como forma de vencer as perseguições no reino. Em 1591, seria enviada a primeira visitação do Santo Ofício ao Brasil, vasculhando heresias e maus comportamentos cristãos pelas capitanias da Bahia, Itamaracá, Pernambuco e Paraíba até 1595. Na documentação oriunda desta visitação encontram-se inúmeros indícios do criptojudaísmo que era praticado, em sua grande parte ligado a ritos, prática da "esnoga" (reuniões judaizantes), cultos funerários, interdições alimentares, formas de benzer heterodoxas, negações à religião dominante em seus símbolos e dogmas, onde, a todo instante, a importância das mulheres salta aos olhos.

É variado o rol de relatos sobre mulheres que insistiam em manter fidelidade ao judaísmo, praticando-o nos momentos de privacidade, embora publicamente, imbuídas dos temores que oprimiam os cristãos-novos, dissimulassem, declarando-se verdadeiras cristãs, embora, obviamente, nem sempre o fossem.

Por todos os lugares, as mulheres neoconversas tentavam, dentro do possível, a manutenção da antiga fé, dissumulando (ou nem tanto assim) suas preferências religiosas. Muitas vezes, temendo denúncias e procurando mostrar boa vontade com a Inquisição. Foi assim que, em 1565, Brites Fernandes, mulher viúva de sessenta e cinco anos, moradora em Lisboa, procuraria o Santo Ofício para confessar que "ela andava errada na fé de nosso senhor Jesus Cristo de quinze ou dezesseis anos a esta parte, parecendo-lhe que se salvaria na Lei de Moisés, e que o Messias não era vindo nem o era nosso senhor Jesus Cristo, e que havia de vir outro". Como tal, "se tinha por judia em seu coração neste tempo e se encomendava a deus dos céus". Pela idade de Brites, nascera por volta de 1500, filha de pais batizados em pé poucos anos antes. Provavelmente fôra educada em lar ainda judeu, aprendendo - com os pais, parentes e pessoas próximas - a Lei Antiga, procurando dissimular suas crenças judaicas para não sofrer perseguições. Acabaria reconciliada à Igreja, condenada a pena branda abjuração em forma, penitências espirituais, não sair do reino sem licença dos inquisidores (Inquisição de Lisboa, processo 1112).

Com relação ao Brasil, não foram poucas as denúncias a retratarem esta 
dubiedade vivida pelas cristãs-novas, não só externamente - ora frequentando igrejas, ora reunidas em torno das leis da Torá -, mas também em seu interior, a confundirem muitas vezes a tradição cristã com os ensinamentos judaicos, divididas entre o catolicismo que lhes fôra imposto e o judaísmo que lhes fôra "arrancado a fórceps", desconhecendo ambas em detalhes, praticando-as de forma igualmente equivocada, de acordo com as conveniências e necessidades.

Citemos, como exemplo, alguns casos de comportamentos tidos como judaizantes pela população e denunciados ao Santo Ofício durante a Primeira Visitação. Assim, um certo Francisco Soares, por exemplo, que se dizia "cristãonovo que tem alguma raça de cristão velho", acusaria a mãe, Maria Álvares, e a irmã, Guiomar Soeiro, de mandarem, em caso de falecimento, "lançar fora a água dos potes que estavam na cantareira da sala", tornando a enchê-las de água fresca da fonte (Denunciações e Confissões de Pernambuco, 1984, p. 373-374). Também Isabel Vaz, ao morrer-lhe um escravo em casa, teria dado ordens para "vazar fora a água dos potes que estavam na cozinha" e que fosse trazida nova quantidade de água fresca. Branca Ramires, por sua vez, confessaria o mesmo costume perante o visitador: falecendo um escravo em um corredor da sua sala, "antes de o levarem a enterrar, ela mandou vazar fora a água dos potes da cantareira da sala, donde ela confessante bebia" (Denunciações e Confissões de Pernambuco, 1984, p. 106-107).

As precauções alimentares ganhariam destaque nos livros de confissões e denúncias. A cristã-nova Gracia Fernandes, embora já falecida à época da visitação, seria denunciada pelo filho Gaspar do Casal de seguir algumas das leis dietéticas atribuídas ao judaísmo. Segundo Gaspar: "havendo em casa algumas vezes coelho e enguia para comer, e comendo-os os de casa, nunca a dita sua mãe comeu, dizendo que coelho e enguia não comia ela". A recusa aos alimentos era repetida pela filha Isabel, que, enquanto era solteira, morando na mesma residência da mãe, "nunca comia coelho nem enguia quando o havia em casa" (Denunciações e Confissões de Pernambuco, 1984, p. 147-148).

Já a cristã-nova Violante Pacheca, confessaria práticas atribuídas aos judeus, como a preparação das refeições pelo modo tradicional judaico. Algumas vezes, "tirou a lândoa do quarto traseiro à rês miúda", o que informava fazer por aprender de um cunhado cristão velho "para se assar bem a carne". Mantinha ainda hábito que aprendera com outro cunhado "para ser saborosa a 
panela": "muitas vezes, costuma cozer a panela de carne, quando é magra, com cebola ou alho frito em azeite, e que também isto faz sem ruim tenção". Declarava ainda que, três ou quatro anos antes, quando ainda morava na Paraíba, morreram dois de seus filhos, doentes de boubas, num intervalo de 15 ou vinte dias, "e quando lhe morreram, os dias em que os levaram a enterrar, lançou ela fora a água dos potes, e quebrou os púcaros que estavam nos mesmos potes" (Denunciações e Confissões de Pernambuco, 1984, p. 117-118).

$\mathrm{O}$ costume de vazar a água em caso de falecimento seria repetido por outras mulheres. A cristã-nova Beatriz Mendes confessaria que, cerca de quinze ou dezesseis anos antes, nesta vila deu uma doença de bexigas pelos escravos e negros brasis, de que morriam muitos, da qual doença lhe morreram a ela muitos escravos. E um dia em que lhe morreram dois em casa, que foram os derradeiros que lhe morreram daquela doença peçonhenta e nojenta, depois que os levaram da casa para enterrar, mandou ela confessante lançar fora a água de dois potes que tinha na cantareira, de que bebia, por uma sua escrava, e lavá-los e tornar a trazê-los cheios de água fresca para casa. (Denunciações e Confissões de Pernambuco, 1984, p. 102-104).

Outro importante depoimento seria dado pela cristã velha Catarina de Lemos, que informaria ter ouvido de uma sua comadre que uma certa Catarina Álvares mantinha-se à espera do Messias prometido aos judeus, sem aceitar a Jesus Cristo como o verdadeiro Messias conforme a crença cristã. Em conversa com um mancebo que fora criado no Espírito Santo, teria Catarina Álvares pronunciado o seguinte juramento, esperando o dia de sua redenção e preparando a vingança sobre os que considerava seus opressores: "guai, guai, filho, que inda o Messias não é vindo, e estamos esperando por ele, e como ele vier, estes cañis (sic) destes cristãos velhos hão de ser nossos escravos!" (Denunciações e Confissões de Pernambuco, 1984, p. 142-145)

$\mathrm{Na}$ Bahia, em um dos mais estarrecedores casos envolvendo mulheres acusadas de práticas judaizantes na documentação referente à primeira visitação inquisitorial ao Brasil, a cristã-nova Ana Rodrigues Antunes, natural da região da Serra da Estrela, na Beira interior portuguesa, e moradora em Matoim, no Recôncavo Baiano.

Ana Rodrigues viera do reino com Heitor Antunes, seu marido, senhor de engenho e "cavaleiro da casa del-rei". Segundo diziam, Heitor possuía sinagoga em suas terras no Recôncavo da Bahia há cerca de trinta anos. 
O casal tinha sete filhas, todas casadas com genros de "sangue puro", ou seja, cristãos velhos. Morto o marido, Ana Rodrigues o enterrara segundo a tradição, em terra virgem, pranteando-o pelo modo judaico e dizia-se dela que esperava o momento de poder se juntar novamente ao esposo, guardando as joias que usou no casamento para serem enterradas com ela quando morresse. A chegada da visitação da Inquisição acabaria com a tranquilidade da família, seguidamente acusada de criptojudaísmo e de desrespeito à fé católica. Dentre os Antunes, seria Ana, de longe, aquela denunciada com maior gravidade e insistência, sofrendo mais de quarenta acusações ao todo. Conscientes de que seriam denunciados, alguns membros da família aproveitariam o período da graça para confessar os erros, adiantando-se à avalanche de acusadores do clã, mostrar boa vontade com o Santo Ofício e amenizar as culpas que lhes eram imputadas, procurando, sem sucesso, arrumar desculpas para tudo.

Judaizante ao extremo e mulher de mais de oitenta anos, era conhecida pelas blasfêmias que pronunciava. O parentesco bíblico, de que outrora se orgulhava o marido, era agora símbolo do escárnio público de que era vítima ao lado das filhas, chamadas pejorativamente de "Macabeias". Suas histórias geravam escândalo. No batismo de uma bisneta, teria Ana afirmado: "olhai que negro batismo"! Quando de um dos partos de suas filhas, clamando-se por Nossa Senhora, dissera, "não me faleis nisso que não o posso dizer!" (Denunciações da Bahia, 1925, p. 275-276). Uma parenta cristã velha contaria sobre a octogenária matriarca que, adoecida certa vez, "suas filhas lhe mostravam um crucifixo e que ela o não queria ver, dizendo: tirai-o lá", recebendo o auxílio de um filho para livrar-se da incômoda presença. $\mathrm{O}$ receio de ter a crença proibida desvendada e da rejeição social daí decorrente levaria uma de suas filhas a retrucar: "mãe, não nos desonreis porque somos casadas com homens cristãos velhos e nobres". Quando em lucidez, tentava, assim como as filhas, manter as aparências, "sendo devotas de Nossa Senhora e fazendo romarias, indo às igrejas, dando esmolas e fazendo outras boas obras de boas cristãs" (Denunciações da Bahia, 1925, p. 250-251). Apesar do esforço dissimulatório, aos olhos populares sua residência era transformada em verdadeiro templo judaico, onde ensinava as tradições da antiga lei aos filhos.

A velha senhora seria acusada de judaísmo, e seus denunciantes desfilariam 
o rol de suas culpas repetidas vezes. Com mais veemência, seria delatada por guardar o dia sagrado dos judeus, não comer certos tipos de alimento, jurar pelo mundo que tem a alma do marido e guardar-lhe luto ao modo dos judeus, lançar a água de casa fora em caso de falecimento, fazer jejuns e orações judaicas, movimentando o corpo à maneira dos judeus, recusar um crucifixo quando doente, e benzer filhos e netos escorregando-lhes a mão pelo rosto. Outros parentes próximos da anciã - principalmente filhos e netos - confessariam ou seriam acusados de algumas destas práticas, embora em nenhum caso tenha se repetido o mesmo número de acusações que pesavam sobre a matriarca da família. O envolvimento de filhos, netos e sobrinhos nas acusações de judaísmo permite-nos vislumbrar o grau de complexidade do fenômeno criptojudaico entre os Antunes, por meio da preservação de várias tradições do judaísmo de "portas para dentro", reproduzidas no ambiente doméstico e transmitidas às novas gerações, embora estes costumes sofressem uma espécie de "filtragem" na recepção, com o abandono crescente de algumas destas práticas pelos descendentes, na tentativa de ocultar a fé proibida.

Ciente das críticas sociais ao seu comportamento e temendo as presumíveis denúncias contra seus desregramentos ao inquisidor, a matriarca dos Antunes compareceria ao Tribunal para confessar algumas de suas práticas de judaísmo, mas para tudo apresentando desculpas, afirmando desconhecer-lhes a herética origem: não comia carne de arraia e cação fresco por fazer-lhe mal ao estômago, mas que antes da doença, os comia; ao morrer-lhe um filho lançara fora a água dos potes, ficando "os primeiros oito dias sem comer carne", o que lhe ensinara uma comadre cristã velha; jurava "pelo mundo que tem a alma de meu pai, ou de meu marido, ou de meu filho", mas sem entender "ser juramento de judeus". Estarrecido, o visitador parecia não aceitar as explicações, alertando-a de "que está mui forte a presunção contra ela, que é judia e vive na lei de Moisés", posto não ser "possível fazer todas as ditas cerimônias de judeus, tão conhecidas e sabidas", sem lhes conhecer a origem, "e que por isso fica claro que ela é judia e que as fez como judia” (VAINFAS, 1997, p. 281286). Desmascarada, a velha senhora seria presa e enviada numa jaula ao Tribunal de Lisboa, enquanto seus genros cristãos velhos e fidalgos tentavam em vão provar sua inocência. Idosa e doente, vingar-se-ia da prisão morrendo no cárcere, o que não a livraria de ser condenada ao "braço secular" e relaxada em 
efígie, tendo sua memória amaldiçoada e os ossos desenterrados, "queimados e feitos em pó em detestação de tão grande crime". Para evitar que seu exemplo fosse repetido, um quadro retratando-a entre labaredas e seres demoníacos ficaria exposto na igreja de Matoim, onde morara, a mando do Santo Ofício. Além da matriarca Macabeia, outros familiares sofreriam acusações, e alguns deles, seriam processados pela Inquisição: Heitor Antunes, seu falecido marido; Beatriz, Violante e Leonor, suas filhas, e a neta, Ana Alcoforado.

Sua condenação traria, afora as complicações sociais para os membros da família, afamados como judaizantes e/ou coniventes e acobertadores de práticas criptojudaicas, um outro agravante para seus descendentes: os bens em nome da velha senhora seriam confiscados pela Inquisição, o que levaria os seus genros, anos depois, em 1600, a apresentarem, pessoalmente, diversas petições em Lisboa para revisão da pena, novamente alegando idade avançada e insanidade da velha matriarca, procurando não só limpar o nome da família, mas recuperar os bens tomados pelos inquisidores para continuar os negócios do clã na Bahia. Como define Elias Lipiner (1969, p. 137), a jurisdição do Tribunal da fé não se extinguia com as labaredas da fogueira em que eram sacrificadas suas vítimas. Não parava em quem fora por ele condenado, mas estendia-se aos descendentes vivos para serem diretamente atingidos, proibindo-se-lhes o exercício de ofícios públicos e certas profissões liberais, e expondo-os, particularmente, à malevolência pública.

Durante a segunda visitação inquisitorial ao Brasil, iniciada em 1618, seriam ainda ouvidos ecos do irregrado comportamento dos Antunes, novamente apontados ao visitador como grupo judaizante. As histórias sobre Ana Rodrigues e seus descendentes ainda permaneceriam vivas na memória e eram repetidas, ocasionando o tal roubo da imagem que representava a matriarca queimando no inferno da porta da Igreja de Matoim, na tentativa desesperada de preservar sua memória e a de seus familiares, poupando os descendentes da velha Macabeia de maior infâmia.

Grandes nomes desta resistência judaica, seja em Portugal ou na colônia, tanto nossa Ana Rodrigues quanto as outras mulheres aqui citadas, dentre tantas e tantas outras, alcançadas ou não pelo Santo Ofício, conhecidas ou não, foram das representantes máximas do criptojudaísmo brasílico no século XVI. Como elas, outras mulheres viveriam ambiguamente, divididas entre o cato- 
licismo que repudiavam e o hebraísmo que lhes era vedado, desconhecendo a fundo ambos, praticando ora um, ora outro, de acordo com o local e as conveniências. Mártires da religião proibida, sofreriam pressões, ofensas, calúnias e discriminações enquanto lutavam para manter vivos e retransmitir os ideais da religião oculta que insistiam em manter, exemplo claro de suas identidades marranas.

\section{Referências}

LIPINER, Elias. Os judaizantes nas capitanias de cima: estudos sobre os cristãos-novos do Brasil nos séculos XVI e XVII. São Paulo: Brasiliense, 1969.

NOVINSKY, Anita. Cristãos Novos na Bahia: 1624-1654. São Paulo: Perspectiva/Ed. da Universidade de São Paulo, 1972.

Primeira Visitação do Santo Officio às partes do Brasil pelo licenciado Heitor Furtado de Mendonça capellão fidalgo del Rey nosso senhor e do seu desembargo, deputado do Santo Officio. Denunciações da Bahia (1591-1593). São Paulo: Paulo Prado, 1925.

Primeira Visitação do Santo Oficio às Partes do Brasil. Denunciações e Confissões de Pernambuco (1593-1595). Recife: FUNDARPE. Diretoria de Assuntos Culturais, 1984, Coleção Pernambucana, $2^{\text {a }}$ fase, vol. XIV.

SIQUEIRA, Sonia. A Inquisição portuguesa e a sociedade colonial. São Paulo: Ática, 1978.

VAINFAS, Ronaldo. “'Deixai a lei de Moisés!' Notas sobre o Espelho de cristãos-novos (1541), de frei Francisco Machado". In: GORENSTEIN, Lina; CARNEIRO, M. L. Tucci. Ensaios sobre a Intolerância. Inquisição, Marranismo e Anti-Semitismo. 2a . ed. São Paulo: Associação Editorial Humanitas, 2005.

. (Org.) Confissões da Bahia: O Santo Ofício da Inquisição de Lisboa. São Paulo: Companhia das Letras, 1997. 